\title{
Locally-advanced unresected uterine leiomyosarcoma with triple-modality treatment combining radiotherapy, chemotherapy and hyperthermia: A case report
}

\author{
AYA SHIRAFUJI $^{1,2}$, AKIKO SHINAGAWA ${ }^{1}$, TETSUJI KUROKAWA ${ }^{1}$ and YOSHIO YOSHIDA ${ }^{1}$ \\ ${ }^{1}$ Department of Obstetrics and Gynecology, Faculty of Medical Sciences, University of Fukui; \\ ${ }^{2}$ Department of Obstetrics and Gynecology, Fukui Aiiku Hospital, Fukui, Japan
}

Received October 17, 2013; Accepted May 7, 2014

DOI: $10.3892 / \mathrm{ol} .2014 .2193$

\begin{abstract}
Advanced uterine leiomyosarcoma (LMS) is a rare and extremely aggressive disease. In patients with advanced and unresected uterine LMS, multidisciplinary therapy is the best treatment option, although no consensus exists on the efficacy of the treatment. The present study describes the case of a 41-year-old female who underwent laparotomy due to a large uterine tumor. Exploratory laparotomy revealed a large tumor that had extended from the pelvic wall to the outside of the pelvis and then invaded the colon. Large residual tumors remained present in the pelvis following suboptimal debulking surgery. Subsequent to surgery, the patient was treated with adjuvant radiotherapy, followed by chemotherapy with regional whole pelvis hyperthermia (HT). Computed tomography revealed stable disease prior and subsequent to combination treatment. While treatment was being administered for third/fourth-degree burns and subcutaneous fatty necrosis, the patient developed multi-organ failure and succumbed. The present case report describes the potential for using a combination of chemotherapy, HT and radiotherapy in patients with LMS. The development of an effective protocol is required for the administration of chemotherapy, HT and radiotherapy in patients with advanced unresected LMS.
\end{abstract}

\section{Introduction}

Uterine leiomyosarcoma (LMS) is a rare and extremely aggressive disease. In patients with advanced LMS, the five-year survival rate is $<20 \%$. In addition, suboptimal primary surgery that induces tumor injury and a cut-through

Correspondence to: Professor Yoshio Yoshida, Department of Obstetrics and Gynecology, Faculty of Medical Sciences, University of Fukui, 23-3 Matsuoka-Shimoaizuki, Eiheiji-cho, Yoshida-gun, Fukui 910-1193, Japan

E-mail: yyoshida@u-fukui.ac.jp

Key words: advanced leiomyosarcoma, radiation therapy, chemotherapy, hyperthermia of the uterine sarcoma is associated with a worse prognosis compared with complete resection of the uterine sarcoma $(1,2)$.

In patients with advanced and unresected uterine LMS, multidisciplinary therapy is the best treatment option for the extension of life. For treatment using chemotherapy subsequent to radiotherapy, numerous agents have been investigated in patients with LMS, however, results have been unsatisfactory (Table I) (3-16). A number of studies have shown that chemotherapy-based treatments may have potential in patients with LMS through the simultaneous use of hyperthermia (HT) and drugs (17-20). However, to the best of our knowledge, there have been no studies on the treatment with radiotherapy followed by a combination of chemotherapy and HT in patients with locally-advanced, unresected uterine LMS. To the best of our knowledge, the present study is the first to report the use of these three modalities for the treatment of locally-advanced, unresected uterine LMS.

\section{Case report}

Patient presentation. A 41-year old female (gravida 2, para 2) presented to the University of Fukui Hospital (Fukui, Japan) with prolonged uterine bleeding and lower abdominal fullness. The patient had previously been treated for a large symptomatic leiomyoma with monthly injections of a long-acting gonadotropin-releasing hormone $(\mathrm{GnRH})$ agonist at the Fukui Aiiku Hospital (Fukui, Japan). Upon examination, the patient appeared anemic and had a palpable abdominal mass that was the same size as the head of a newborn child. Magnetic resonance imaging revealed a large, heterogeneously hyperintense mass in the T1- and T2-weighted images of the pelvic cavity. Despite these abnormal findings, the patient selected conservative treatment in order to preserve fertility and due to the previous good response to GnRH agonist treatment. The patient was administered monthly injections of $1.88 \mathrm{mg}$ leuprolide acetate. Prior to the third injection, an increase in the size of the uterine mass was observed, and two weeks after the injection the patient presented with abdominal pain, bleeding and leg edema. The patient subsequently decided to undergo surgery. 


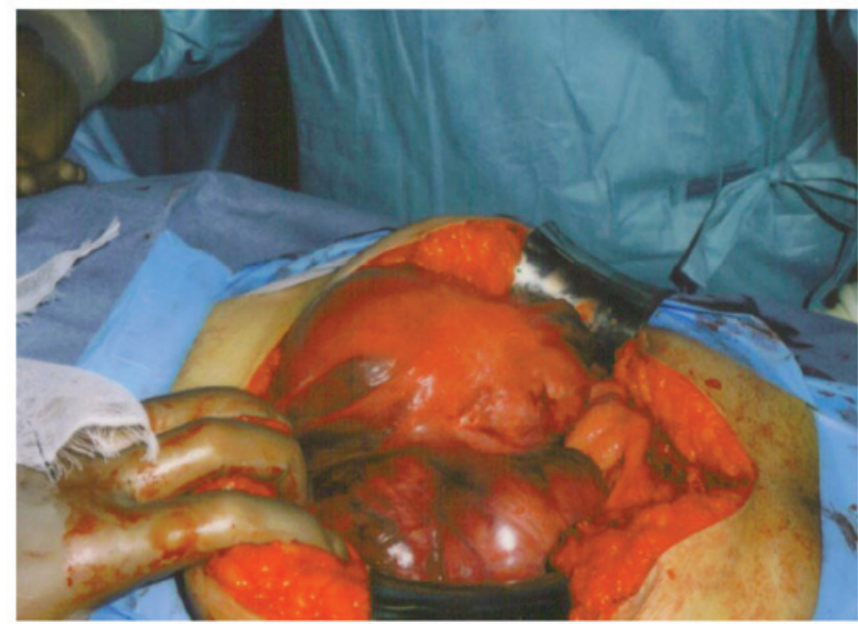

Figure 1. Exploratory laparotomy revealed a large tumor extending outside of the pelvis and invading the colon.

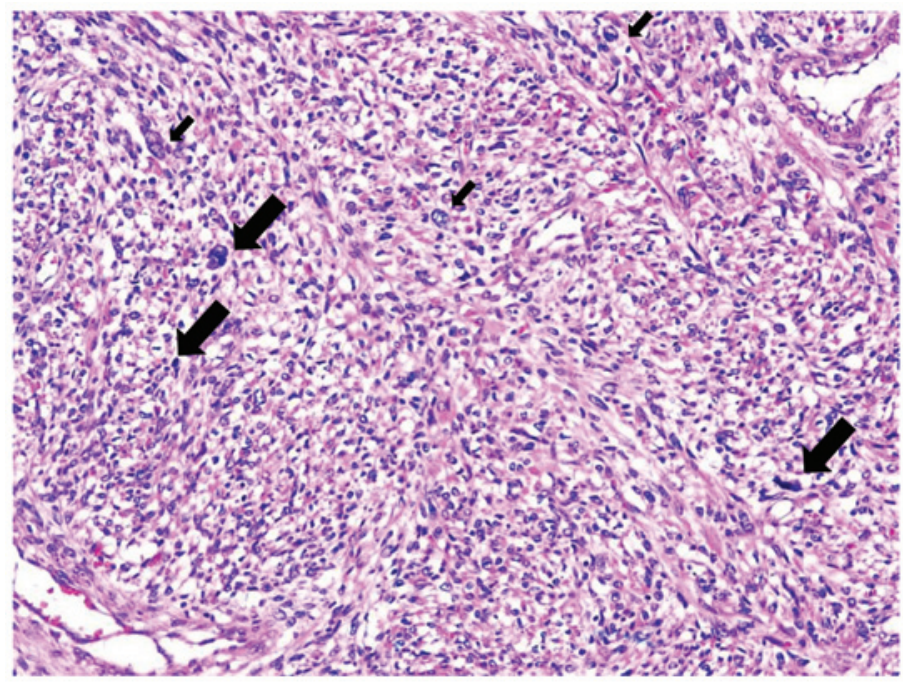

Figure 2. Surgical specimen showing smooth muscle cells with nuclear atypia (small arrows) and a high mitotic index, with $>10$ mitotic figures per high power field (large arrows). Hematoxylin and eosin staining; magnification, x20.

Surgery. Exploratory laparotomy revealed a large tumor that had extended from the pelvic wall to the outside of the pelvis and then invaded the colon (Fig. 1). Suboptimal debulking was performed, with a supra-hysterectomy and resection of the metastatic masses. Large residual tumors remained in the pelvis. Microscopically, the mass was composed of an LMS component with nuclear atypia and a high mitotic index (Fig. 2) and a leiomyoma component.

Adjuvant chemotherapy and radiotherapy. Following suboptimal debulking surgery, the patient presented with lower abdominal pain and continuous vaginal bleeding. A previous study showed that radiotherapy improves the local status of uterine sarcomas (21), thus, subsequent to obtaining informed consent, adjuvant radiotherapy was administered, followed by chemotherapy at the University of Fukui Hospital. The patient received 15-MV external-beam radiotherapy to the whole pelvis at a dose of $50.4 \mathrm{~Gy}$, in five fractions of $1.8 \mathrm{~Gy}$ per week, using a four-field box technique according to our institutional protocol. Computed tomography (CT) revealed stable disease (SD) according to the Response Evaluation Criteria in Solid Tumors (RECIST), prior and subsequent to radiotherapy. Two weeks after radiotherapy, the patient received intravenous gemcitabine $\left(900 \mathrm{mg} / \mathrm{m}^{2}\right.$ administered over $90 \mathrm{~min}$ on days 1 and 8) and docetaxel $\left(75 \mathrm{mg} / \mathrm{m}^{2}\right.$ on day 8$)$ with granulocyte growth factor support on day 9 of a 21-day cycle to be scheduled every three weeks. Based on the results of the previous radiotherapy (15), a $25 \%$ lower dose of docetaxel was administered. Following three months of gemcitabine and docetaxel chemotherapy, the patient was hospitalized due to grade II pulmonary toxicity. The patient was treated with antibiotics and showed marked improvement. Subsequent to a further three months of receiving the same chemotherapy, the patient was readmitted with grade II pulmonary toxicity. The patient was again treated with antibiotics and showed marked improvement. A CT scan revealed the SD status of the LMS according to the RECIST, prior and subsequent to the six months of chemotherapy.

HT treatment. Based on the patient's tumor response, toxicity and performance status, HT was added to the chemotherapy 
Table I. Review of the schedules of chemotherapy followed by radiotherapy used to treat patients with leiomyosarcoma of the uterus in previous studies.

\begin{tabular}{|c|c|c|c|c|}
\hline Drug & $\mathrm{A} / \mathrm{B}$ & Schedule & $\begin{array}{l}\text { Response } \\
\text { rate, \% }\end{array}$ & First author (year) [ref] \\
\hline \multirow[t]{2}{*}{ Gemcitabine } & $20 / 31$ & $\begin{array}{l}1,250 \mathrm{mg} / \mathrm{m}^{2} \text { on days } 1 \\
\text { and } 8 \text { in a } 3 \text {-weekly schedule }\end{array}$ & 3.23 & Svancarova L et al (2002) [3] \\
\hline & $15 / 29$ & $\begin{array}{l}1,250 \mathrm{mg} / \mathrm{m}^{2} \text { every week } \mathrm{x} \text { three, } \\
\text { cycles repeated every } 28 \text { days }\end{array}$ & 3 & Okuno S et al (2002) [4] \\
\hline Paclitaxel & $15 / 48$ & $\begin{array}{l}135 \mathrm{mg} / \mathrm{m}^{2} \text { for patients with } \\
\text { prior radiotherapy every } 3 \text { weeks }\end{array}$ & 8.4 & Gallup DG et al (2003) [5] \\
\hline Trabectedin & $21 / 36$ & $\begin{array}{l}\text { A } 24-\mathrm{h} \text { continuous iv infusion } \\
\text { at a dose of } 1.5 \mathrm{~g} / \mathrm{m}^{2} \text { every } 3 \text { weeks }\end{array}$ & 8 & Garcia-Carbonera R et al (2004) [6] \\
\hline Trimetrexate & $7 / 23$ & $\begin{array}{l}5 \mathrm{mg} / \mathrm{m}^{2} / \text { day orally for } 5 \text { days } \\
\text { every other week }\end{array}$ & 4.3 & Smith HO et al (2002) [7] \\
\hline \multirow[t]{2}{*}{ Etoposide } & $6 / 29$ & $\begin{array}{l}30-40 \mathrm{mg} / \mathrm{m}^{2} / \text { day for prior radiotherapy } \\
\text { as a single dose for } 21 \text { days, every } 28 \text { days }\end{array}$ & 6.9 & Rose PG et al (1998) [8] \\
\hline & $7 / 28$ & $100 \mathrm{mg} / \mathrm{m}^{2}$ orally ond ays 1,3 and 5 & 11 & Slayton RE et al (1987) [9] \\
\hline Amonafide & $8 / 26$ & $300 \mathrm{mg} / \mathrm{m}^{2} \times 5$ days every 3 weeks & 4 & Asbury R et al (1998) [10] \\
\hline
\end{tabular}

B, Combination

\begin{tabular}{|c|c|c|c|c|}
\hline Drug & $\mathrm{A} / \mathrm{B}$ & Schedule & $\begin{array}{c}\text { Response } \\
\text { rate, \% }\end{array}$ & First author (year) [ref] \\
\hline $\begin{array}{l}\text { Dacarbazine + Mitimycin + } \\
\text { Doxorubicine + Cisplatin }\end{array}$ & $7 / 18$ & $\begin{array}{l}\text { Day } 0 \text { consisting of dacarbazine } 750 \mathrm{mg} / \mathrm{m}^{2} \\
\text { iv over } 2 \mathrm{~h} \text {, mitomycin } 6 \mathrm{mg} / \mathrm{m}^{2} \text { iv over } 2-5 \mathrm{~min} \text {, } \\
\text { doxorubicin } 40 \mathrm{mg} / \mathrm{m}^{2} \text { iv over } 2-5 \mathrm{~min} \text { and cisplatin } \\
60 \mathrm{mg} / \mathrm{m}^{2} \text { iv over } 2 \mathrm{~h} \text {, retreated at } 4 \text {-week intervals }\end{array}$ & 27.8 & Long HJ III et al (2005) [11] \\
\hline $\begin{array}{l}\text { Mitimycin + Doxorubicine } \\
+ \text { Cisplatin }\end{array}$ & $8 / 35$ & $\begin{array}{l}\text { Mitomycin } 8 \mathrm{mg} / \mathrm{m}^{2} \text { and doxorubicin } 40 \mathrm{mg} / \mathrm{m}^{2} \\
\text { each by iv injection, followed by cisplatin } 60 \mathrm{mg} / \mathrm{m}^{2} \\
\text { by } 2 \text {-h iv at } 3 \text {-week intervals }\end{array}$ & 23 & Edmonson JH et al (2002) [12] \\
\hline $\begin{array}{l}\text { Hydroxyurea + Dacarbazine } \\
+ \text { Etoposide }\end{array}$ & $11 / 32$ & $\begin{array}{l}\text { Hydroxyurea } 2 \mathrm{~g} \text { in divided doses on day } 1 \text {, } \\
700 \mathrm{mg} / \mathrm{m}^{2} \text { dacarbazine and } 100 \mathrm{mg} / \mathrm{m}^{2} \text { etoposide } \\
\text { on day } 2 \text { and } 100 \mathrm{mg} / \mathrm{m}^{2} \text { etoposide on days } 3 \text { and } 4\end{array}$ & 18 & Currie J et al (1996) [13] \\
\hline Ifosfamide + Doxorubicin & $9 / 34$ & $\begin{array}{l}\text { Ifosfamide, } 5.0 \mathrm{~g} / \mathrm{m}^{2} / 24 \mathrm{~h} \text {, and mesna, } \\
6.0 \mathrm{~g} / \mathrm{m}^{2} / 36 \mathrm{~h}, \text { by continuous iv infusion preceded } \\
\text { by doxorubicin, } 50 \mathrm{mg} / \mathrm{m}^{2} \text { iv over } 15 \mathrm{~min} \\
\text { Each course of therapy was repeated every } 3 \text { weeks }\end{array}$ & 30.3 & Sutton G et al (1996) [14] \\
\hline Gemcitabine + Docetaxel & $14 / 34$ & $\begin{array}{l}\text { Gemcitabine } 900 \mathrm{mg} / \mathrm{m}^{2} \text { iv on days } 1 \text { and } 8 \\
\text { plus docetaxel } 100 \mathrm{mg} / \mathrm{m}^{2} \text { iv on day } 8 \\
\text { delivered every } 21 \text { days } \\
\text { ( } 25 \% \text { lower doses if prior radiotherapy) }\end{array}$ & 53 & Hensley ML et al (2002) [15] \\
\hline Gemcitabine + Docetaxel & $17 / 39$ & $\begin{array}{l}\text { Gemcitabine } 900 \mathrm{mg} / \mathrm{m}^{2} \text { iv on days } 1 \text { and } 8 \\
\text { plus docetaxel } 100 \mathrm{mg} / \mathrm{m}^{2} \text { iv on } \\
\text { day } 8 \text { delivered every } 21 \text { days }\end{array}$ & 27 & Hensley ML et al (2008) [16] \\
\hline
\end{tabular}

$\mathrm{A} / \mathrm{B}$, number of patients prior to radiotherapy/number of all patients; iv, intravenous.

regimen subsequent to obtaining informed consent. Regional whole pelvis HT was administered in the same week that the patient received gemcitabine $\left(900 \mathrm{mg} / \mathrm{m}^{2}\right.$ administered over $90 \mathrm{~min})$ and docetaxel $\left(75 \mathrm{mg} / \mathrm{m}^{2}\right)$. Thermometry catheters were placed in the rectum, bladder and vagina for thermal dose calculations. Following appropriate adjustments to the treatment settings, the power output was increased until the patient's tolerance threshold was reached. HT treatment was administered for 60 min after vaginal measurements had reached $40^{\circ} \mathrm{C}$. Subsequent to 6 weeks of HT with chemotherapy, the patient was hospitalized with grade III burns and subcutaneous fatty necrosis. Therefore, HT treatment was withdrawn. CT revealed SD of the LMS according to the RECIST, prior and subsequent to six months of receiving the combination of HT and chemotherapy. While treatment was being administered for the grade III/IV burns and 
subcutaneous fatty necrosis, the patient developed multi-organ failure and succumbed.

\section{Discussion}

Adujuvant pelvic radiotherapy may improve local pelvic control, but dose not improve patient survival (21). Thus, in patients with symptomatic (for example exhibiting vaginal bleeding), unresected or advanced LMS, radiotherapy is optimal.

In patients with advanced or unresected LMS, systemic treatment is the best option for the extension of life. Table I shows an overview of the clinical trials of chemotherapy followed by radiotherapy used to treat patients with advanced LMS in previous studies. Gemcitabine and docetaxel are the most common agents used for non-primary chemotherapy in patients with recurrent and advanced uterine sarcoma. Hensley et al (15) performed a phase II trial of gemcitabine and docetaxel in patients with unresectable LMS. The study included patients who had received prior pelvic radiation, those who had become worse following doxorubicin-based therapy and those who had not received prior chemotherapy. A $25 \%$ lower dose of the two agents was administered to the patients who had received prior pelvic radiation. A complete response or a partial response (PR) were observed in $53 \%$ of the enrolled patients. Hematological toxicity was common, while neutropenic fever and bleeding were rare (15). In the present case, the patient received $25 \%$ lower doses of gemcitabine and docetaxel, as the patient had received prior pelvic radiation treatment. Although PR was not observed and the side-effects were acceptable, for patients who have undergone prior treatment, particularly radiotherapy, the use of $25 \%$ lower doses of gemcitabine and docetaxel should be considered.

Research into LMS continues to focus on the identification of active drugs and treatment combinations. A number of studies have shown the potential for a response to chemotherapy by the simultaneous use of HT and drugs (17-20). Wiedemann et al (17) reported that whole body hyperthermia (WBH) may enhance the therapeutic index of specific chemotherapeutic agents, such as ifosfamide, carboplatin and etoposide (ICE), resulting in a response rate of 63\% (17). However, Pereira Arias et al (18) reported the development of an acute systemic inflammatory response syndrome with multiple organ dysfunction syndrome following administration of WBH in combination with ICE. If chemotherapic agents and hyperthemia are selected appropriately, for example, changing WBH to whole-pelvic HT, HT with chemotherapy may be a safe and useful procedure for the treatment of locally-advanced cervical cancer. Westerman et al (19) reported that the combination of full-dose radiotherapy, chemotherapy and HT is a feasible and effective treatment strategy for patients with advanced cervical carcinoma without concessions to radiotherapy, chemotherapy or HT dose, compared with patients receiving single- or combined-modality treatment. Additionally, Mohamed et al (20) reported that HT increased the cytotoxicity of docetaxel and gemcitabine in mouse fibrosarcoma. Thus, in the present study, a compounding effect was expected with the combination of docetaxel, gemcitabine and HT for the patient with unresected LMS who had undergone prior radiotherapy. In the present case, this combination had moderate efficacy.
The cytotoxicity of these drugs is synergized by heat, but the timing between the chemotherapy and HT may not have been adequate for the present patient. For the concomitant use of radiotherapy, chemotherapy and HT for the treatment of patients with cervical carcinoma, Westermann et al (19) advised that chemotherapy and HT should be administered concurrently, preferentially $1 \mathrm{~h}$, but no more than $6 \mathrm{~h}$, prior to radiotherapy. The optimal sequence of the administration of these three therapeutic modalities for the treatment of LMS has yet to be elucidated. The analysis of an effective protocol is required for the administration of chemotherapy, HT and radiotherapy in patients with unresected LMS.

In the present case, the combination of HT with chemotherapy was effective, however, grade III/IV burns and subcutaneous fatty necrosis toxicity occurred. At present, no consensus exists on the efficacy of treatment for locally-advanced, unresected uterine LMS. The present case study described the potential for a combination treatment using chemotherapy, HT and radiotherapy. In conclusion, further investigation is required into an effective protocol for the administration of chemotherapy, HT and radiotherapy in patients with unresected LMS.

\section{References}

1. Park JY, Park SK, Kim DY, et al: The impact of tumor morcellation during surgery on the prognosis of patients with apparently early uterine leiomyosarcoma. Gynecol Oncol 122: 255-259, 2011.

2. Leitao MM Jr, Zivanovic O, Chi DS, et al: Surgical cytoreduction in patients with metastatic uterine leiomyosarcoma at the time of initial diagnosis. Gynecol Oncol 125: 409-413, 2012.

3. Svancárová L, Blay JY, Judson IR, et al: Gemcitabine in advanced adult soft-tissue sarcomas. A phase II study of the EORTC Soft Tissue and Bone Sarcoma Group. Eur J Cancer 38: 556-559, 2002.

4. Okuno S, Edmonson J, Mahoney M, et al: Phase II trial of gemcitabine in advanced sarcomas.Cancer 94: 3225-3229, 2002.

5. Gallup DG, Blessing JA, Andersen W and Morgan MA; Gynecologic Oncology Group Study: Evaluation of paclitaxel in previously treated leiomyosarcoma of the uterus: a gynecologic oncology group study. Gynecol Oncol 89: 48-51, 2003.

6. Garcia-Carbonero R, Supko JG, Manola J, et al: Phase II and pharmacokinetic study of ecteinascidin 743 in patients with progressive sarcomas of soft tissues refractory to chemotherapy. J Clin Oncol 22: 1480-1490, 2004.

7. Smith HO, Blessing JA and Vaccarello L: Trimetrexate in the treatment of recurrent or advanced leiomyosarcoma of the uterus: a phase II study of the Gynecologic Oncology Group. Gynecol Oncol 84: 140-144, 2002.

8. Rose PG, Blessing JA, Soper JT and Barter JF: Prolonged oral etoposide in recurrent or advanced leiomyosarcoma of the uterus: a gynecologic oncology group study.Gynecol Oncol 70: 267-271, 1998.

9. Slayton RE, Blessing JA, Angel C and Berman M: Phase II trial of etoposide in the management of advanced and recurrent leiomyosarcoma of the uterus: a Gynecologic Oncology Group Study. Cancer Treat Rep 71: 1303-1304, 1987.

10. Asbury R, Blessing JA, Buller R, et al: Amonafide in patients with leiomyosarcoma of the uterus: a phase II Gynecologic Oncology Group study. Am J Clin Oncol 21: 145-146, 1998.

11. Long HJ III, Blessing JA and Sorosky J: Phase II trial of dacarbazine, mitomycin, doxorubicin, and cisplatin with sargramostim in uterine leiomyosarcoma: a Gynecologic Oncology Group study. Gynecol Oncol 99: 339-342, 2005.

12. Edmonson JH, Blessing JA, Cosin JA, et al: Phase II study of mitomycin, doxorubicin, and cisplatin in the treatment of advanced uterine leiomyosarcoma: a Gynecologic Oncology Group study. Gynecol Oncol 85: 507-510,2002. 
13. Currie J, Blessing JA, Muss HB, Fowler J, Berman M and Burke TW: Combination chemotherapy with hydroxyurea, dacarbazine (DTIC), and etoposide in the treatment of uterine leiomyosarcoma: a Gynecologic Oncology Group study. Gynecol Oncol 61: 27-30, 1999.

14. Sutton G, Blessing JA and Malfetano JH: Ifosfamide and doxorubicin in the treatment of advanced leiomyosarcomas of the uterus: a Gynecologic Oncology Group study. Gynecol Oncol. 62: 226-229, 1996

15. Hensley ML, Maki R, Venkatraman E, Geller G, Lovegren M, Aghajanian C, Sabbatini P, Tong W, Barakat R and Spriggs DR: Gemcitabine and docetaxel in patients with unresectable leiomyosarcoma: results of a phase II trial. J Clin Oncol 20: 2824-2831, 2002.

16. Hensley ML, Blessing JA, Degeest K, Abulafia O, Rose PG and Homesley HD: Fixed-dose rate gemcitabine plus docetaxel as second-line therapy for metastatic uterine leiomyosarcoma: a Gynecologic Oncology Group phase II study. Gynecol Oncol 109: 323-328, 2008

17. Wiedemann GJ, Robins HI, Katschinski DM, et al: Systemic hyperthermia and ICE chemotherapy for sarcoma patients: rationale and clinical status. Anticancer Res 17: 2899-2902, 1997.
18. Pereira Arias AM, Wester JP, Blankendaal M, et al: Multiple organ dysfunction syndrome induced by whole-body hyperthermia and polychemotherapy in a patient with disseminated leiomyosarcoma of the uterus. Intensive Care Med 25: 1013-1016, 1999.

19. Westermann AM, Jones EL, Schem BC, et al. First results of triple-modality treatment combining radiotherapy, chemotherapy, and hyperthermia for the treatment of patients with stage IIB, III, and IVA cervical carcinoma. Cancer 104: 763-770, 2005.

20. Mohamed F, Marchettini P, Stuart OA, et al: Thermal enhancement of new chemotherapeutic agents at moderate hyperthermia. Ann Surg Oncol 10: 463-468, 2003.

21. Reed NS, Mangioni C, Malmström H, et al: Phase III randomised study to evaluate the role of adjuvant pelvic radiotherapy in the treatment of uterine sarcomas stages I and II: an European Organisation for Research and Treatment of Cancer Gynaecological Cancer Group Study (protocol 55874). Eur J Cancer 44: 808-818, 2008. 